\title{
Both raw and retrograded starch decrease serum triacylglycerol concentration and fat accretion in the rat
}

\author{
BY EMILE A. M. DE DECKERE*, WILLEM J. KLOOTS \\ AND JOHAN M. M. VAN AMELSVOORT \\ Unilever Research Laboratorium Vlaardingen, Olivier van Noortlaan 120, 3133 AT Vlaardingen, \\ The Netherlands
}

(Received 31 January 1994 - Revised 23 May 1994 - Accepted 24 June 1994)

\begin{abstract}
Male Wistar rats were meal-fed on diets containing various amounts of resistant starch in the form of raw starch (either amylomaize starch, potato starch or modified high-amylose starch) or retrograded starch (prepared from each of the starches) for 6 weeks. Two diets containing normal maize starch were fed as diets poor in resistant starch. Energy absorption (energy consumption minus faecal energy loss), growth, weight of the epididymal fat pads, serum total cholesterol and triacylglycerol concentrations and a number of intestinal and faecal variables were determined. The resistant starches affected all the variables determined except the serum total cholesterol concentration. Relationships were found between energy absorption and both growth and the weight of the fat pads, and between the weight of the fat pads and both the serum triacylglycerol concentration and the serum total cholesterol concentration. No clear differences between the effects of the two types of resistant starch (raw starch v. retrograded starch) were found except that raw potato starch hardly stimulated $\mathrm{H}_{2}$ excretion and led to lower amounts of propionic and butyric acids in the caecal contents than the other starches. The results suggest that dietary resistant starch reduces energy absorption leading to less abdominal depot fat and lower serum triacylglycerol concentrations.
\end{abstract}

Energy metabolism: Lipid metabolism: Resistant starch

Lipid and carbohydrate metabolism of man have developed in the evolutionary process on the basis of natural food containing, in addition to non-starch polysaccharides (dietary fibre), indigestible or $\alpha$-amylase (EC 3.2.1.1)-resistant starch (RS). For this reason RS and non-starch polysaccharides may be important for appropriate functioning of lipid and carbohydrate metabolism of humans in the long term. RS has been defined as the sum of starch and starch-degradation products not absorbed in the small intestine. It may have a number of physiological effects similar to those of non-starch polysaccharides, such as the reduction of plasma cholesterol, and increases in caecal and large intestinal contents and faecal mass. These effects, as hypothesized for non-starch polysaccharides, may contribute to the decrease in the incidence of atherosclerosis, large bowel cancer and obesity. Three types of RS have been classified: physically inaccessible starch (cell-wall-enclosed), $\alpha$ amylase-resistant starch granules (a number of raw, native starches), and retrograded starch (mainly amylose; Englyst $e t$ al. 1992). In previous studies we found that feeding diets containing a high amount of retrograded starch led to lower serum triacylglycerol and total cholesterol concentrations and epididymal fat pad weights (De Deckere et al. 1992, 1993). In the present study we have investigated the effects of raw and retrograded starch on a number of variables, in particular on energy absorption, and whether energy absorption may be involved in the effects of RS on the serum triacylglycerol and cholesterol

- For reprints. 
concentrations. The raw starches used were: uncooked Hylon VII (amylomaize starch), potato starch and Ultra-set (a modified, high-amylose maize starch). Uncooked, normal maize starch (Meritena starch) was used as a highly-digestible starch. Retrograde starch was prepared from pregelatinized Hylon VII, cooked potato starch and cooked Ultra-set. Meritena starch treated in the same way was used as a starch with a low amount of retrograded starch.

\section{MATERIALS AND METHODS}

Animals, diets and feeding procedures

All animal experimental procedures were approved by the Animal Experiments Committee of the Unilever Research Laboratorium. Male Wistar rats (WU-strain, SPF, age 9-10 weeks, initial body weight about $300 \mathrm{~g}$ ) were purchased from Harlan/CPB (Zeist, The Netherlands). They were housed individually in cages with wire-mesh bottoms in airconditioned rooms $\left(23^{\circ} \pm 1\right.$, relative humidity $\left.\pm 55 \%\right)$, and acclimatized for 1 week, followed by training for a meal-eating regimen (free access to food from 07.00 to 07.30 hours and from 19.00 to 19.30 hours) for another week. In these 2 weeks the rats had free access to a non-purified diet (RMH-B; Hope Farms, Woerden, The Netherlands). At the end of the 2 weeks, serum total cholesterol concentrations and body weights were determined and the rats were divided into eight different groups each consisting of eight rats with similar mean serum total cholesterol concentration and body weight. After the 2 weeks the experimental diets (Table 1) were fed for 6 weeks (weeks 1-6). The diets were prepared daily, except at the weekends, by mixing raw or gelatinized starch with the other ingredients. For the weekends the diets were prepared on Friday and stored at $+5^{\circ}$. The rats had free access to tap water. A fixed day-night rhythm was applied (light from 07.00 to 19.00 hours). At the end of the experimental feeding period the rats were killed by decapitation between 09.00 and 10.30 hours.

\section{Analyses}

Hydrogen excretion. $\mathrm{H}_{2}$ excretion was determined between day 6 and day 16 from 08.00 to 16.00 hours as described previously (De Deckere et al. 1993).

Feed consumption and faeces collection. Feed consumption was determined for four consecutive days in week 4 . Faeces were collected over the same period and stored at $-20^{\circ}$.

Caecal contents. The $\mathrm{pH}$ of the caecal contents was determined immediately after removal of the contents from the caecum in a water-diluted sample using a pH meter (type E603; Metrohm, Herisau, Switzerland). Samples were stored at $-20^{\circ}$.

Resistant and total starch. RS in the raw and gelatinized starch preparations (after freezing and thawing of the gels, except the gel of cold-water-soluble (CWS)-Hylon VII which was not frozen; Table 2) was determined as the difference between the amount of total starch and the amount of starch hydrolysed for $6 \mathrm{~h}$ with a mixture of pancreatin (8 U/mg; Fluka, Buchs, Switzerland), amyloglucosidase (EC 3.2.1.3; $14 \mathrm{U} / \mathrm{mg}$; Boehringer, Mannheim, Germany) and invertase (EC 3.2.1.26; $3000 \mathrm{EU} / \mathrm{ml}$; BDH, Poole, Dorset; Englyst et al. 1992). Sodium azide (1.2 mmol/1) was present to inhibit bacterial growth. Total starch in freeze-dried caecal contents and faeces were determined according to Berry (1986). Briefly, starch was dissolved in $\mathrm{KOH}(2 \mathrm{~mol} / \mathrm{l})$, and after neutralization of the solution to $\mathrm{pH} 6.7$, hydrolysed by $\alpha$-amylase $(1000 \mathrm{U} / \mathrm{mg}$, Boehringer) and amyloglucosidase at $37^{\circ}$ for $16 \mathrm{~h}$. Glucose was determined by using a hexokinase (EC 2.7.1.1) method (Boehringer) and a Cobas Mira S analyzer (Hoffmann-La Roche, Basel, Switzerland).

Serum total cholesterol and triacylglycerol concentrations. Both before and at the end of the experimental feeding period, total cholesterol and triacylglycerol concentrations were determined in tail blood obtained just before the start of the morning meal by using the Boehringer assays for total cholesterol and triacylglycerol (De Deckere et al. 1993). 
Table 1. Composition of experimental diets (g)

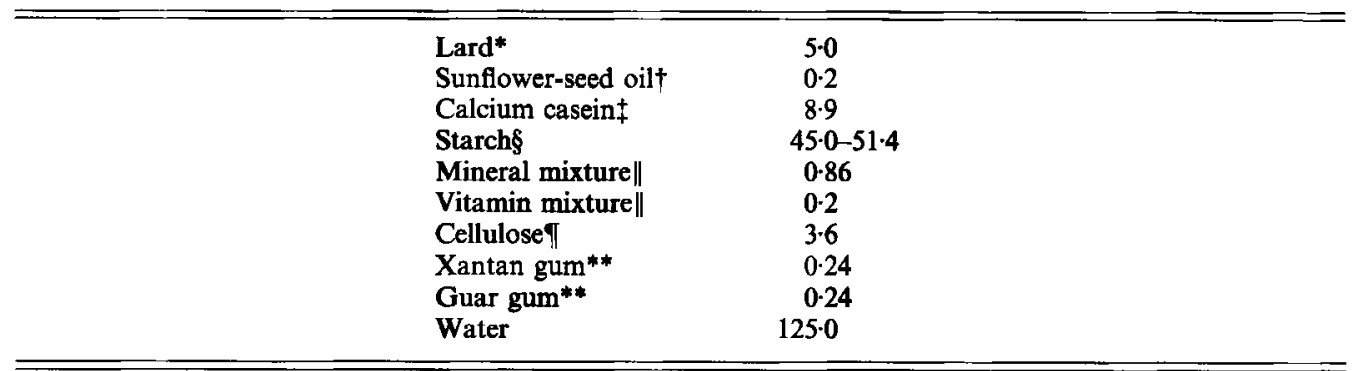

* Smilde BV, Heerenveen, The Netherlands.

+ Union NV, Merksem, Belgium.

$\ddagger$ DMV, Veghel, The Netherlands; protein 910 , fat $9 \mathrm{~g} / \mathrm{kg}$.

$\$$ See Table 2.

\|t De Deckere et al. (1993).

TI Machery-Nagel GmbH, Dueren-Roelsdorg, Germany; short type of fibre.

** Xantan gum (Keltrof-TF, Danby Chemie, Amsterdam, The Netherlands) and guar gum (Meypro-Guar, CSAA M-225, Meyhall Chemical AG, Kreuzlingen, Switzerland) were added in order to stabilize the porridges with the raw starches.

Table 2. Type and amount of dietary starch, amount of resistant starch (RS), and gross dietary energy $(G D E)$ of the diets

\begin{tabular}{|c|c|c|c|c|c|c|}
\hline \multirow{2}{*}{$\begin{array}{c}\text { Group } \\
\text { no. }\end{array}$} & \multicolumn{3}{|c|}{ Starch } & \multicolumn{2}{|l|}{ RS } & \multirow[b]{2}{*}{ GDE $\ddagger(\mathrm{kJ} / \mathrm{g})$} \\
\hline & Source & Form* & Dietary level $+(\mathrm{g})$ & $\mathrm{mg} / \mathrm{g}$ total starch & $\mathrm{mg} / \mathrm{g}$ diet & \\
\hline 1 & Hylon VIIß & Raw & $48 \cdot 2$ & 650 & 137 & $5 \cdot 73$ \\
\hline 2 & CWS-Hylon VII & Gel & $45 \cdot 0$ & 370 & 82 & 5.96 \\
\hline 3 & Meritena AT & Raw & $48 \cdot 2$ & 5 & 1 & 5.82 \\
\hline 4 & & Gel & 48.2 & 17 & 4 & 5.82 \\
\hline 5 & Potato starch** & Raw & $51 \cdot 4$ & 670 & 143 & 5.74 \\
\hline 6 & & Gel & $51 \cdot 4$ & 240 & 51 & 5.74 \\
\hline 7 & Ultra-set LT†† & Raw & $48 \cdot 2$ & 90 & 20 & 5.99 \\
\hline 8 & & Gel & $48 \cdot 2$ & 240 & 54 & 5.99 \\
\hline
\end{tabular}

* Preparation of the gels was as follows: $1 \mathrm{~kg}$ starch was suspended in approximately 2.6 litres tap water. CWSHylon VII was gelatinized with water at room temperature before food preparation. Meritena $A$ and potato starch were fully gelatinized at $70^{\circ}$ for $5 \mathrm{~min}$. Ultra-set LT was fully gelatinized at $95^{\circ}$ for $45 \mathrm{~min}$ under stirring. The suspensions were cooled down by standing at room temperature. Retrograded starch was prepared as follows: the gels of Meritena A, potato starch and Ultra-set were placed at $-20^{\circ}$ for $1-6 \mathrm{~d}$, after which they were thawed by standing at room temperature. The gelatinized starch was particulated by this procedure making the gels easy to mix with the other food ingredients.

+ See Table 1.

$\ddagger$ Assuming the following energy contents $(\mathrm{kJ} / \mathrm{g})$ : fat $38 \cdot 9$, protein $17 \cdot 2$, carbohydrates $17 \cdot 2$.

$\S$ Native amylomaize starch containing approximately $700 \mathrm{mg}$ amylose $/ \mathrm{g}$ total starch, and $160 \mathrm{mg}$ water/g; National Starch and Chemical Company, Zutphen, The Netherlands.

$\|$ Cold-water-soluble (CWS), extruded Hylon VII containing $70 \mathrm{mg}$ water/g; National Starch and Chemical Company.

\$ Common maize starch containing $140 \mathrm{mg}$ water/g; N. V. Honig's Artikelen, Koog a/d Zaan, The Netherlands.

** Native, free-flowing potato starch containing $190 \mathrm{mg}$ water/g; AVÉBÉ, Veendam, The Netherlands.

t† Modified maize starch containing approximately $420 \mathrm{mg}$ amylose/g total starch (De Deckere et al. 1993), and $100 \mathrm{mg}$ water/g; National Starch and Chemical Company. 
Short-chain fatty acids (SCFA). Caecal (200 mg) and faecal (500 mg) samples were homogenized in 1 and $5 \mathrm{ml}$ water respectively, after which 2.5 and $0.6 \mu \mathrm{mol}$ ethyl butyric acid (Merck, Darmstadt, Germany) respectively were added. After mixing, the homogenates were centrifuged at $2500 \mathrm{~g}$ for $15 \mathrm{~min}$. Portions of the supernatant fractions were mixed with 5 vol. ethanol, and the resulting precipitates removed by centrifugation. The $\mathrm{pH}$ of $1 \mathrm{ml}$ samples was raised to $10-11$ with $\mathrm{NaOH}$, and the samples were extracted with $2 \mathrm{ml}$ $n$-heptane. The heptane fraction was removed and the ethanol-water mixture evaporated with a stream of $\mathrm{N}_{2}$ at $37^{\circ}$. The residue was dissolved in phosphoric acid $(1 \mathrm{~mol} / \mathrm{l})$, immediately before analysis by GLC. Samples were injected into a Perkin Elmer (Beaconsfield, Bucks.) gas-liquid chromatograph using split injection. The gas-liquid chromatograph was equipped with a WCOT Fused Silica FFAP CB column with a film thickness of $0.3 \mu \mathrm{m}(25 \mathrm{~m} \times 0.32 \mathrm{~mm}$; Chrompack, Middelburg, The Netherlands) and a fused silica retention cap $(2.5 \mathrm{~m} \times 0.32 \mathrm{~mm}$, Chrompack). SCFA were detected using a flame-ionization detector. The temperatures of the injection port and detector were 220 and $250^{\circ}$ respectively. The oven temperature was kept at $115^{\circ}$ for $4 \mathrm{~min}$ before the temperature was raised $30^{\circ}$ per min to $220^{\circ}$. Concentrations of SCFA were calculated by using ethyl butyric acid as internal standard and a response factor for each SCFA. Each series of analyses included a control sample consisting of a pooled sample of faeces.

Faecal fat excretion. Total fat in faeces was determined according to a standard procedure (Folch et al. 1957).

\section{Calculation of apparent starch digestibility, apparent energy absorption and resistant starch consumption}

Apparent starch digestibility and apparent energy absorption (starch digestibility and energy absorption respectively) were calculated using the values for feed consumption and faeces production determined in week 4 . Starch digestibility was calculated as the proportion of starch ingested that was not later recovered in the faeces. Energy absorption was calculated as gross energy consumption minus the energy lost in the faeces. Gross energy consumption was calculated as the product of feed consumption and the gross energy per $g$ feed. The latter value was calculated from the amounts of fat, protein and carbohydrate in the diets and their energy values (Tables 1 and 2). The energy lost in the faeces was calculated as the sum of the amount of faecal starch multiplied by $17 \cdot 2 \mathrm{~kJ} / \mathrm{g}$, and the dry weight of the faeces minus the faecal starch multiplied by $19 \mathrm{~kJ} / \mathrm{g}$. The latter value is the energy value of faeces of rats fed on a comparable semi-synthetic diet without RS (bomb calorimetry; E. J. Brink, unpublished results). Energy loss due to $\mathbf{H}_{2}$ excretion was $0.4 \%$ or less of the energy of the total dietary starch and was neglected. RS consumption was calculated as the product of feed consumption and the amount of RS in the feed.

\section{Statistics}

Statistical analysis was performed by using Statistical Analysis Systems (1987) procedure. Data were analysed by one-way ANOVA. Differences between the groups were established using the Student-Newman-Keuls multiple-range test. Significance was assessed at the $P$ $<0.05$ level. Relationships (between groups) between the amount of dietary RS (mg/g feed) and dependent variables, and mutual relationships (within groups with group as classification factor) between dependent variables were analysed by the general linear models procedure.

\section{RESULTS}

\section{Resistant starch}

As mentioned previously, the amount of RS in the starch preparations was determined by the method of Englyst et al. (1992) as the difference between total and digestible starch 
RESISTANT STARCH AND LIPID METABOLISM

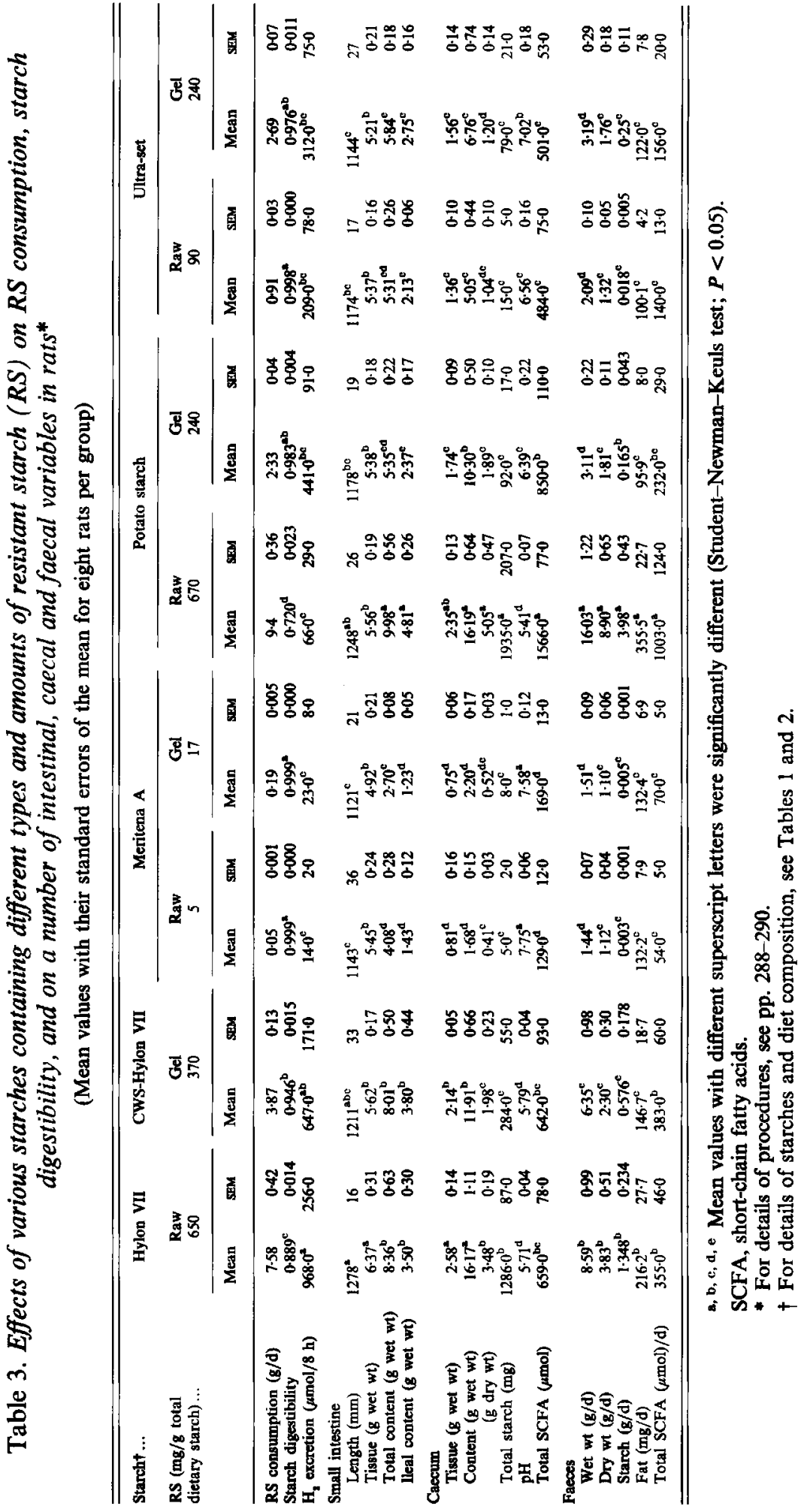


(a)

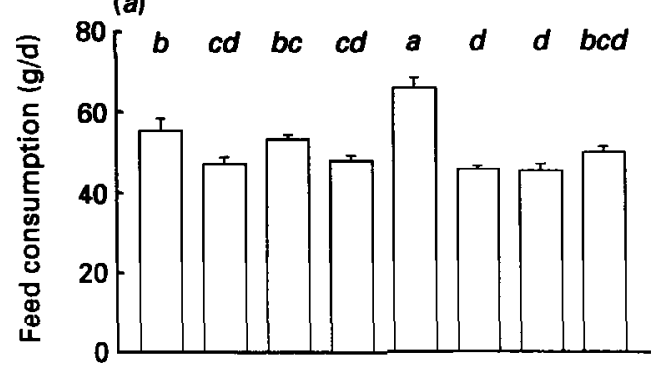

(c)

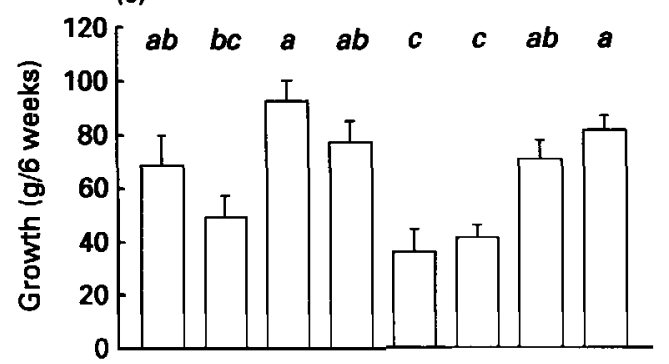

(e)

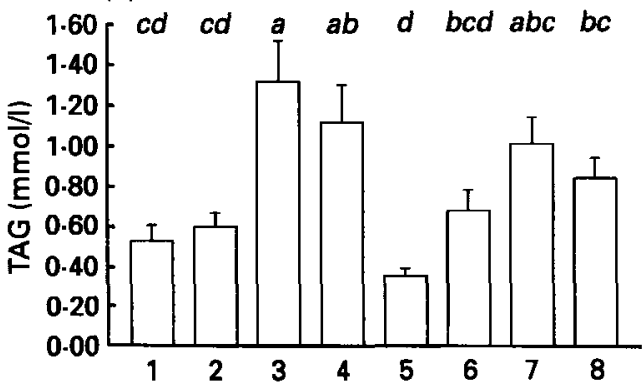

(b)

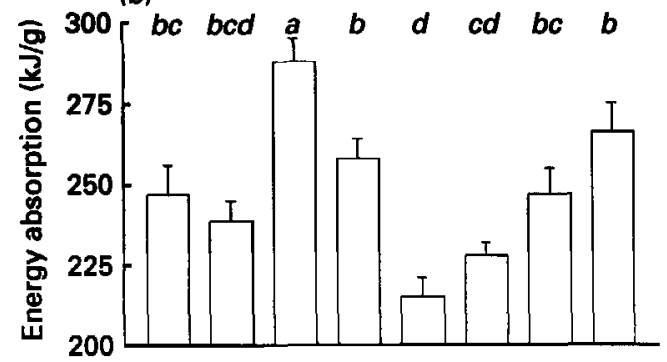

(d)

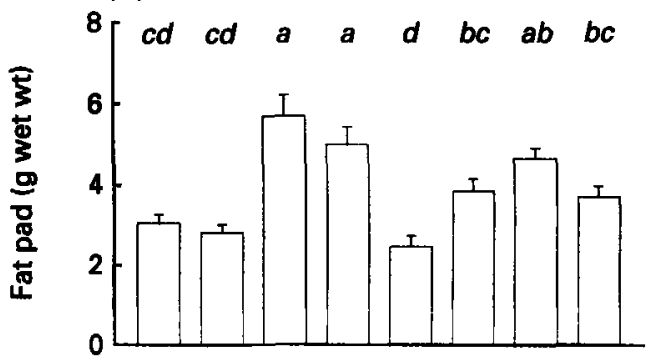

(f)

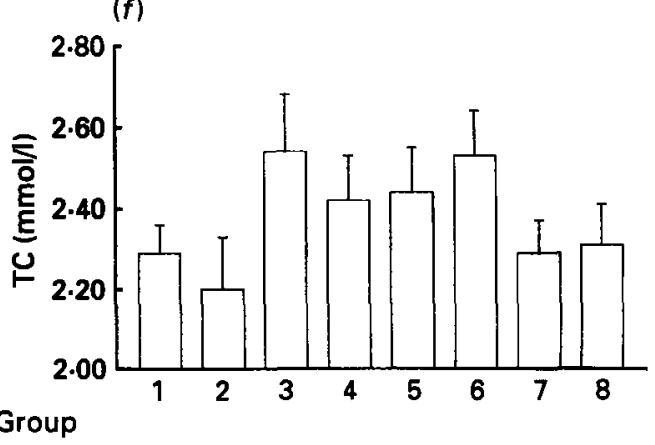

Fig. 1. (a) Feed consumption, (b) energy absorption, $(c)$ growth, $(d)$ weight of the epididymal fat pads, $(e)$ serum triacylglycerol (TAG) concentration and $(f)$ serum total cholesterol TC) concentration of rats receiving different types and amounts of resistant starch. Group 1, raw Hylon VII; group 2, gel cold-water-soluble Hylon VII; groups 3 and 4, raw and gel Meritena A respectively; groups 5 and 6, raw and gel potato starch respectively; groups 7 and 8, raw and gel Ultra-set LT respectively. For details of starches and diets, see Tables 1 and 2. Values are means with their standard errors represented by vertical bars. a, b, c, d Values with unlike superscript letters were significantly different (Student-Newman-Keuls test; $P<0.05$ ). For details of procedures, see pp. 288-290.

(Table 2). However, instead of an incubation period of $2 \mathrm{~h}$, as in the original method, the amount of digestible starch was determined after $6 \mathrm{~h}$ incubation because after $2 \mathrm{~h}$ incubation only $74 \%$ of raw Meritena starch was hydrolysed. After 4 and $6 \mathrm{~h}$ incubation, 94 and $99.5 \%$ of raw Meritena starch was hydrolysed respectively. Because raw Meritena starch was well digested in vivo (Table 3), $2 \mathrm{~h}$ incubation was evidently too short, and $6 \mathrm{~h}$ incubation appeared to be appropriate for the hydrolysis of all or nearly all the digestible starch of raw Meritena in the in vitro assay.

\section{Feed and resistant starch consumption}

Feed consumption (g/d) was highest in the raw-potato starch group (group 5), followed by that in the raw-Hylon VII group (group 1), the groups with the largest amounts of dietary 

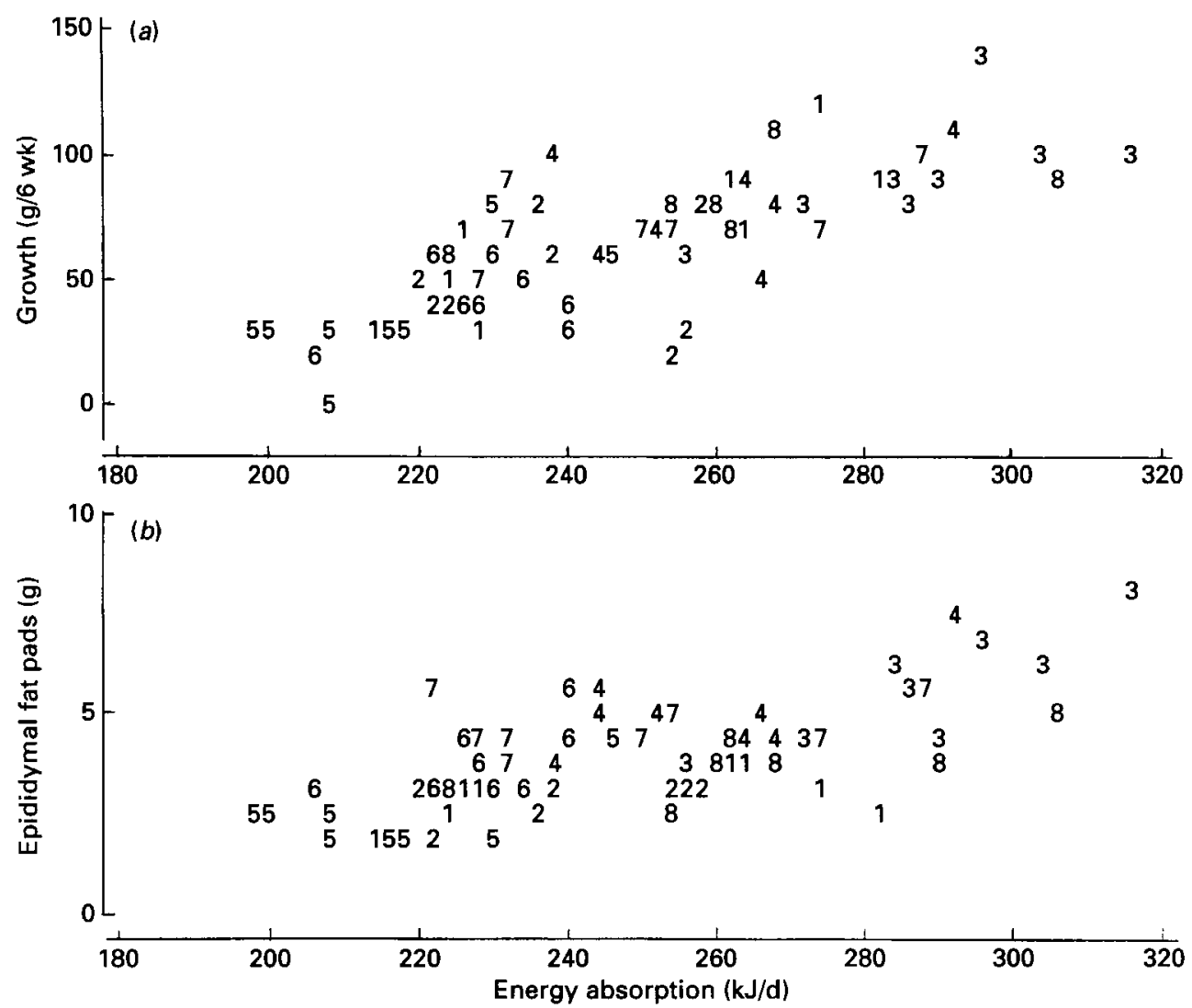

Fig. 2. Correlation between energy absorption and $(a)$ growth, and $(b)$ the weight of the epididymal fat pads in all rats $(n$ 64) receiving different types and amounts of resistant starch. Individual values are denoted by their dietary group: group 1, raw Hylon VII; group 2, gel cold-water soluble Hylon VII; groups 3 and 4, raw and gel Meritena A respectively; groups 5 and 6, raw and gel potato starch respectively; groups 7 and 8, raw and gel Ultraset LT respectively. For details of starches and diets, see Tables 1 and 2. For details of procedures, see pp. 288-290.

RS (Fig. 1 (a)). However, the feed consumption of the raw-Hylon VII group (group 1) was not significantly different from that of the raw-Meritena and Ultra-set-gel groups (groups 3 and 8 ). In addition, feed consumption was positively related to the amount of dietary RS at the level of $P=0.07$ ). The mean values for the daily RS consumption are listed in Table 3. It should be noted that in this variable the factor feed consumption is present.

\section{Energy absorption, growth and weight of epididymal fat pads}

Energy absorption was the highest in the raw-Meritena group (group 3) and the lowest in the two potato-starch groups (groups 5 and 6). The energy absorptions of the other groups did not differ significantly (Fig. $1(b)$ ). The effects of the starch on growth and on the weight of the epididymal fat pads were similar (see Fig. $1(c, d)$ ). Growth was significantly lower in the potato-starch groups (groups 5 and 6) compared with growth in the other groups, except in the CWS-Hylon VII group (group 2). The weight of the fat pads was significantly higher in the Meritena groups (groups 3 and 4) than in the other groups except in the rawUltra-set group (group 7). In addition, energy absorption $(P=0 \cdot 07)$, growth $(P=0 \cdot 10)$, and the weight of the fat pads $(P=0.001)$ were inversely related to the amount of dietary RS. Within groups, as expected, energy absorption was significantly related to both growth 

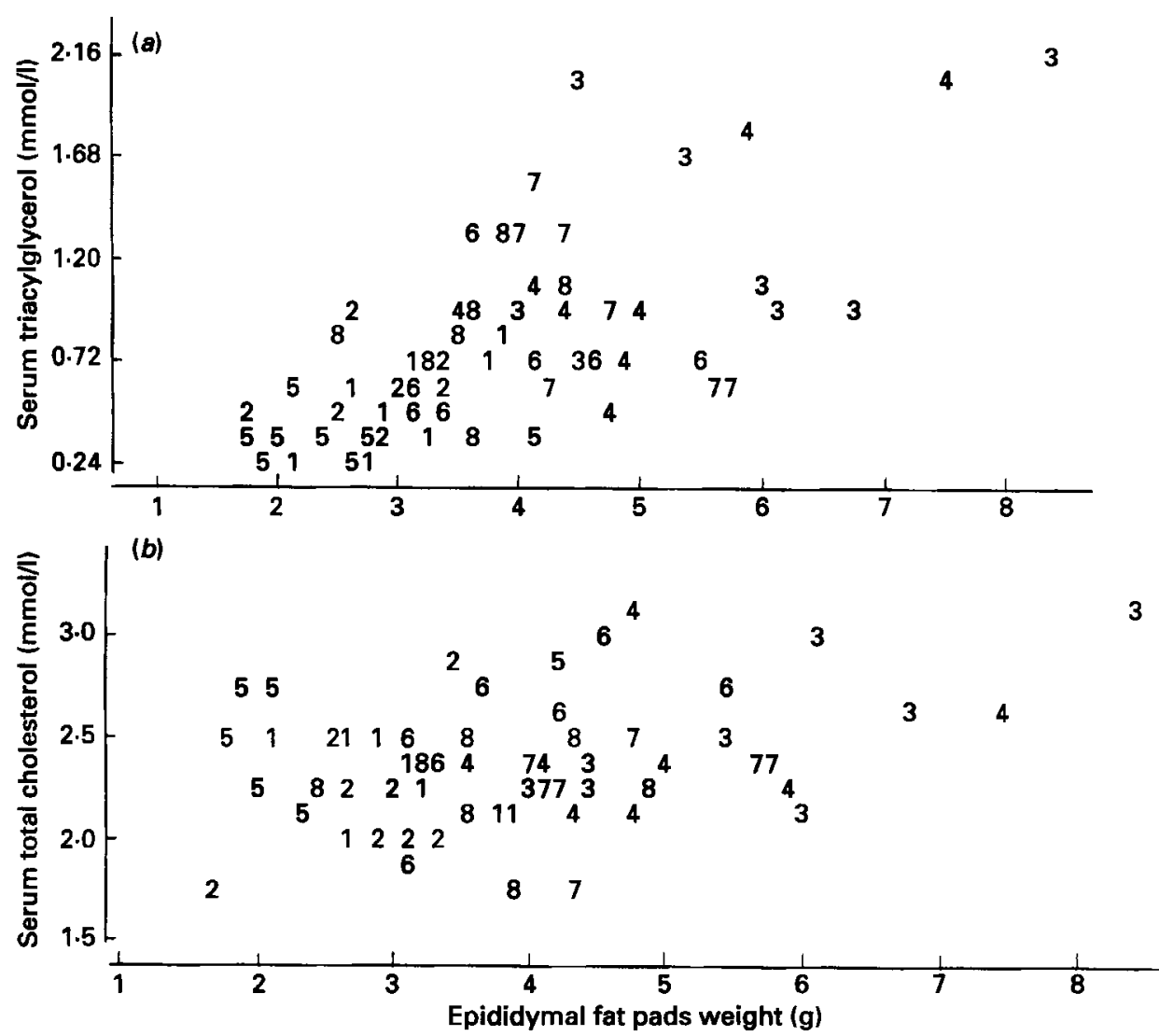

Fig. 3. Correlation between the weight of the epididymal fat pads and (a) the serum triacylglycerol, and $(b)$ total cholesterol concentration in all rats $(n 64)$ receiving different types and amounts of resistant starch. Individual values are denoted by their dietary group number: group 1, raw Hylon VII; group 2, gel cold-water-soluble Hylon VII; groups 3 and 4, raw and gel Meritena A respectively; groups 5 and 6, raw and gel potato starch respectively; groups 7 and 8, raw and gel Ultra-set LT respectively. For details of starches and diets, see Tables 1 and 2 . For details of procedures, see pp. 288-290.

$(P=0.0001)$ and the weight of the fat pads $(P=0.0001)$. The data are plotted in Fig. $2(a$ and $b$ ). These results show that the energy absorption as calculated by us was an appropriate variable.

\section{Serum triacylglycerol and cholesterol concentrations}

The serum triacylglycerol concentration was the highest in the raw-Meritena group (group 3 ) and the lowest in the raw-potato-starch group (group 5; Fig. $1(e)$ ). The effects of the starches on the serum triacylglycerol concentration, energy absorption, and the weight of the fat pads were similar (see Fig. $1(c, d$ and $e$ )). No significant differences between the serum total cholesterol concentrations in the eight groups were found (Fig. $1(f)$ ). The serum triacylglycerol concentration $(P=0.001)$, but not the serum total cholesterol concentration $(P=0.5)$, was related to the amount of dietary RS. Within groups, both the serum triacylglycerol and the total serum cholesterol concentration showed significant relationships with the weight of the fat pads $(P<0.01)$. The data are plotted in Fig. $3(a$ and $b$ ). No significant relationships between the serum lipid concentrations and the other variables determined were found. 
Small intestinal, caecal and faecal variables and starch digestibility

The starch affected the tissue weights and contents of the small intestine and caecum (Table 3). Furthermore, appreciable amounts of starch were found in the caecal contents and faeces, particularly in the Hylon VII groups and the raw-potato starch group resulting in low starch digestibilities. The starch also affected fermentation, leading to increases in $\mathbf{H}_{2}$ excretion, SCFA production and faeces production, and a lowering of the caecal $\mathrm{pH}$. However, the $\mathrm{H}_{2}$ production of the raw-potato starch group was low and not different from that of the Meritena groups. A relatively high amount of acetic acid (93\%) and relatively low amounts of propionic (2\%) and butyric acid (5\%) were present in the caecal contents of the raw-potato starch group, whereas in the maize-starch groups the average values were: acetic acid $71 \%$, propionic acid $15 \%$, butyric acid $12 \%$. As expected, the intestinal and faecal variables determined, except the caecal $\mathrm{pH}$ and $\mathbf{H}_{2}$ excretion, showed significant positive relationships with the amount of dietary RS (between groups) and RS consumption (within groups; $P<0.04$ ). The caecal $\mathrm{pH}$ showed a significant inverse relationship with the dietary RS amount $(P=0.002)$, whereas $\mathrm{H}_{2}$ excretion did not show a significant relationship, probably, because raw potato starch did not increase $\mathrm{H}_{2}$ excretion.

\section{DISCUSSION}

Replacing highly-digestible starch in the diet of rats by RS can lower the serum glucose and insulin concentrations (Morand et al. 1992), and the serum total cholesterol and triacylglycerol concentrations (Carroll et al. 1978; Démigné \& Rémésy, 1982; Sacquet et al. 1983; Morand et al. 1992, Mathé et al. 1993). Similar effects of RS in test meals or in complete diets were found in humans (Behall et al. 1989; Bornet et al. 1989, 1990). We have also found that high-RS diets led to lower serum triacylglycerol and total cholesterol concentrations in the rat (De Deckere et al. 1992, 1993). In the present study the effect of RS on postabsorptive serum triacylglycerol concentration was confirmed, but we did not find a significant effect on the serum total cholesterol concentration. This discrepancy may be explained by the fact that in the present study various types of starch and RS were used whereas in our previous studies retrograded starch prepared from amylose-rich starch was used as a type of RS. Retrograded starch may lower the serum cholesterol concentration by several mechanisms, including an increase in faecal bile acid excretion. Starch, as is the case for non-starch polysaccharides, can bind bile acids in vitro (Bianchini et al. 1989). Furthermore, a non-significant increase in faecal bile acid excretion, in addition to a reduction in the serum cholesterol concentration, has been found in rats fed on diets containing amylomaize starch (Sacquet et al. 1983). We have also found that retrograded starch increased faecal bile acid excretion (M. J. F. Verbeek, unpublished results). These findings suggest that $\mathrm{RS}$ obtained from high-amylose starch may bind bile acids in the small intestine, as a result of which faecal bile acid excretion and the serum cholesterol concentration may be affected.

However, not every type of RS can bind bile acids. It is not expected that RS in the form of resistant starch granules (such as raw potato starch) binds bile acids, and the effect of raw potato starch on the serum cholesterol concentration, as found by Carroll et al. (1978) and Démigné \& Rémésy (1982), may be explained by another mechanism. In humans a correlation between the serum total cholesterol concentration and the visceral fat:subcutaneous fat ratio has been found, indicating that the abdominal fat mass may be correlated with the serum cholesterol concentration (Fujioka et al. 1987). In the present study we have found that dietary RS, probably as a result of a reduction in energy absorption, affected the weight of the epididymal fat pads, and within the groups a significant positive relationship between the serum cholesterol concentration and the 
weight of the fat pads was found. The relationship can be explained as follows. Adipose tissue mass affects the plasma concentration of the free fatty acids. Some of these fatty acids are incorporated into the triacylglycerols of the very-low-density lipoproteins (VLDL). Furthermore, Morand et al. (1992) have found that dietary RS decreased the free fatty acid concentration in the postabsorptive period. Thus, high-RS diets can lead to both a lower adipose tissue mass and a lower free fatty acid concentration as a result of which the triacylglycerol synthesis in the liver may be reduced. This may lead to fewer VLDL particles. Since RS had no effect on hepatic cholesterol synthesis (De Deckere et al. 1993), this may result in VLDL particles containing more cholesterol per particle. Assuming an unchanged clearance rate of lipoprotein particles, this may mean that cholesterol is removed from the plasma at a faster rate, leading to a lower plasma cholesterol concentration. It will be clear that a reduction in triacylglycerol synthesis will also lead to a lower serum triacylglycerol concentration. Thus, the reduction in the adipose tissue mass by RS can contribute to both lower serum cholesterol and triacylglycerol concentrations.

Because RS can decrease the serum insulin concentration (Morand et al. 1992), the role of insulin in lipid metabolism also has to be considered. Insulin stimulates hepatic triacylglycerol synthesis and adipose tissue lipoprotein lipase. (EC 3.1.1.34). A lower insulin concentration may result in a lower triacylglycerol synthesis and a reduction in triacylglycerol clearance by adipose tissue. However, we found no effect of dietary RS on lipoprotein lipase activity in epididymal fat pad (De Deckere et al. 1993).

The energy available from fermented RS ranges between 9.0 and $9.5 \mathrm{~kJ} / \mathrm{g}$ (Southgate, 1989; Mathers, 1992). In combination with the feeding regimen in which the rats were given two ad lib. meals for $30 \mathrm{~min}$, this might have restricted feed intake, as a result of which there was an inverse relationship between the amount of dietary RS and energy absorption. However, a positive relationship was found between the amount of RS and feed intake. Thus, feed intake of the rats fed on raw potato starch was $44 \%$ higher than that of the rats fed on gelatinized potato starch. Furthermore, the effects of RS on the serum lipid concentrations were also found in ad lib.-fed rats (De Deckere et al. 1993) which shows that the feeding regimen as such does not play a role in the effects of RS on serum lipid concentrations. A reduction in energy absorption produced by $\mathrm{RS}$ was also found by Björck et al. (1987) and Livesey et al. (1990) in rats fed on a restricted diet. The effect of RS on energy absorption may not be caused only by the RS itself, but also by a reduction in protein digestibility evoked by RS, as found by Reussner et al. (1963), Fleming \& Vose (1979), Rao \& Rao (1978) and Livesey et al. (1990). Net protein utilization was inversely correlated with the amylose content of the diet (Rao \& Rao, 1978) and positively correlated with starch digestibility (Fleming \& Vose, 1979). As is the case with non-starch polysaccharides (Borel et al. 1989), we also found an increase in faecal fat excretion by RS. In addition, this effect on fat absorption might also contribute to a reduction in serum lipid concentration, as has been suggested for non-starch polysaccharides.

As far as we know, the effect of RS on fat accretion in rats has only been studied by Livesey et al. (1990). However, although in their study the apparent energy digestibility was lower in the RS groups than in the control group, whereas the gross energy intakes were similar, they did not find an effect of RS on the weight of the epididymal fat pads, and on the total and relative amounts of body fat. The reason why their results differ from ours is not clear. The amount of RS in their diets was approximately $16 \%$ of total carbohydrates. Although less than in our diets, it is not likely that this can explain the discrepancy. An explanation may be that in their study sucrose was used as the only or main carbohydrate source. Sucrose compared with digestible starch has profound effects on plasma insulin concentration and insulin sensitivity, and on fat accretion (Laube et al. 1973; Reiser \& Hallfrisch, 1977; Jorgensen et al. 1978). 
Our results suggest that dietary $\mathrm{RS}$ can reduce plasma triacylglycerol concentration and intra-abdominal fat accretion. Because in humans correlations have been found between the mass of the intra-abdominal fat depots and metabolic aberrations, hypertension and coronary heart disease (Kalkhoff et al. 1983; Lapidus et al. 1984; Fujioka et al. 1987; Rebuffé-Scrive et al. 1990), the effects of RS on lipid metabolism might be of importance in these disorders.

The authors would like to thank L. B. M. Tijburg for analysis of SCFA, and Y. de Bruin, I. M. van Benschop, S. Y. Gielen, H. C. Moret and J. E. C. van Wijk for technical assistance, and A. Wiersma for statistical advice.

\section{REFERENCES}

Behall, K. M., Scholfield, D. J., Yuhaniak, I. \& Canary, J. (1989). Diets containing high amylose vs amylopectin starch: effects on metabolic variables in human subjects. American Journal of Clinical Nutrition 49, 337-344.

Berry, C. S. (1986). Resistant starch: formation and measurement of starch that survives exhaustive digestion with amylolytic enzymes during determination of dietary fibre. Journal of Cereal Science 4, 301-314.

Bianchini, F., Caderni, G., Dolara, P., Fantetti, L. \& Kriebel, D. (1989). Effect of dietary fat, starch and cellulose on fecal bile acids in mice. Journal of Nutrition 119, 1617-1624.

Björck, I., Nyman, M., Pedersen, B., Siljeström, M., Asp, N.-G. \& Eggum, B. O. (1987). Formation of enzyme resistant starch during autoclaving of wheat starch: studies in vitro and in vivo. Journal of Cereal Science 6, 159-172.

Borel, P., Lairon, D., Senft, M., Chautan, M. \& Lafont, H. (1989). Wheat bran and wheat germ: effect on digestion and intestinal absorption of dietary lipids in the rat. American Journal of Clinical Nutrition 49, $1192-1202$.

Bornet, F. R. J., Bizais, Y., Bruley des Varannes, S., Pouliquen, B., Delort Laval, J. \& Galmiche, J. P. (1990). Alpha-amylase $(E C 3.2 .1 .1)$ susceptibility rather than viscosity or gastric emptying rate controls plasma responses to starch in healthy humans. British Journal of Nutrition 63, 207-220.

Bornet, F. R. J., Fontvieille, A.-M., Rizkalla, S., Colonna, P., Blayo, A., Mercier, C. \& Slama, G. (1989). Insulin and glycemic responses in healthy humans to native starches processed in different ways: correlations with in vitro $\alpha$-amylase hydrolysis. American Journal of Clinical Nutrition 50, 315-323.

Carroll, K. K., Hamilton, R. M. G., Huff, M. W. \& Falconer, A. D. (1978). Dietary fiber and cholesterol metabolism in rabbits and rats. American Journal of Clinical Nutrition 31, S203-\$207.

De Deckere, E. A. M., Kloots, W. J. \& Van Amelsvoort, J. M. M. (1992). Effects of a diet with resistant starch in the rat. European Journal of Clinical Nutrition 46, Suppl. 2, S121-S122.

De Deckere, E. A. M., Kloots, W. J. \& Van Amelsvoort, J. M. M. (1993). Resistant starch decreases serum total cholesterol and triacylglycerol concentrations in rats. Journal of Nutrition 123, 2142-2151.

Démigné, C. \& Rémésy, C. (1982). Influence of unrefined potato starch on cecal fermentations and volatile fatty acid absorption in rats. Journal of Nutrition 112, 2227-2234.

Englyst, H. N., Kingman, S. M. \& Cummings, J. H. (1992). Classification and measurement of nutritionally important starch fraction. European Journal of Clinical Nutrition 46, Suppl. 2, S33-S50.

Fleming, S. E. \& Vose, J. R. (1979). Digestibility of raw and cooked starches from legume seeds using the laboratory rat. Journal of Nutrition 109, 2067-2075.

Folch, J., Lees, M. \& Sloane-Stanely, C. H. (1957). A simple method for isolation and purification of total lipids from animal tissue. Journal of Biological Chemistry 226, 497-509.

Fujioka, S., Matsuzawa, Y., Tokunaga, K. \& Tarui, S. (1987). Contribution of intra-abdominal fat accumulation to the impairment of glucose and lipid metabolism in human obesity. Metabolism 36, 54-59.

Jorgensen, C., Hallfrisch, J. \& Reiser, S. (1978). Effect of sucrose and feeding frequency on insulin sensitivity and lipogenic enzyme activities in rats with equivalent growth. Nutrition Reports International 18, 87-98.

Kalkhoff, R. K., Hartz, A. H., Rupley, D., Kissebah, A. H. \& Kelber, S. (1983). Relation of body fat distribution to blood pressure, carbohydrate tolerance, and plasma lipids in healthy obese women. Journal of Laboratory and Clinical Medicine 102, 621-627.

Lapidus, L., Bengtsson, C., Larsson, B., Pennert, K., Rybo, E. \& Sjöström, L. (1984). Distribution of adipose tissue and risk of cardiovascular disease and death: a 12-year follow-up of participants in the population study of women in Gothenborg, Sweden. British Medical Journal 289, 1257-1261.

Laube, H., Klör, H. U., Fussgänger, R. \& Pfeiffer, E. F. (1973). The effect of starch, sucrose, glucose and fructose on lipid metabolism in rats. Nutrition and Metabolism 15, 273-280.

Livesey, G., Davies, I. R., Brown, J. C., Faulks, R. M. \& Southon, S. (1990). Energy balance and energy values of $\alpha$-amylase resistant maize starch and pea starches in the rat. British Journal of Nutrition 63, 467-480.

Mathé, D., Riottot, M., Rostaqui, N., Sacquet, E., Navarro, N., Lécuyer, B. \& Lutton, C. (1993). Effect of 
amylomaize starch on plasma lipoproteins of lean and obese zucker rats. Journal of Clinical Biochemistry and Nutrition 14, 17-24.

Mathers, J. C. (1992). Energy value of resistant starch. European Journal of Clinical Nutrition 46, Suppl. 2, S129-S130.

Morand, C., Rémésy, C., Levrat, M.-A. \& Démigné, C. (1992). Replacement of digestible wheat starch by resistant corn starch alters splanchnic metabolism in rats. Journal of Nutrition 122, 345-354.

Rao, C. N. \& Rao, B. S. N. (1978). Influence of starches from different sources on protein utilization in rats. British Journal of Nutrition 40, 1-8.

Rebuffé-Scrive, M., Anderson, B., Olbe, L. \& Björntorp, P. (1990). Metabolism of adipose tissue in intraabdominal depots in severely obese men and women. Metabolism 39, 1021-1025.

Reiser, S. \& Hallfrisch, J. (1977). Insulin sensitivity and adipose tissue weight of rats fed starch or sucrose diets ad libitum or in meals. Journal of Nutrition 107, 147-155.

Reussner, G., Andros, J. \& Thiessen, R. (1963). Studies on the utilization of various starches and sugars in the rat. Journal of Nutrition 80, 291-298.

Sacquet, E., Leprince, C. \& Riottot, M. (1983). Effect of amylomaize starch on cholesterol and bile acid metabolism in germfree [axenic] and conventional [holoxenic] rats. Reproduction Nutrition Développement 23, 783-792.

Southgate, D. A. T. (1989). The role of the gut microflora in the digestion of starches and sugars: with special reference to their role in the metabolism of the host, including energy and vitamin metabolism. In Dietary Starches and Sugars in Man. A Comparison, pp. 67-87 [J. Dobbing, editor]. London: Springer-Verlag.

Statistical Analysis Systems (1987). SAS User's Guide SAS/STAT Version 6. Cary, NC: SAS Institute Inc. 